\section{A New Method of Recording Ciliary Movement.}

THE rate of vibration of cilia is usually too great to permit of accurate observation with an ordinary microscope unless the light be interrupted at a suitable frequency and for suitable periods of time. If the frequency of vibration be approximately fourteen or more beats per second, the form of each cilium during the two phases of its beat, and the nature of the metachronal waves which pass over the epithelium, can be readily observed by means of a suitable stroboscope. If, however, the frequency of vibration is lower than ten per second, accurate observations of this type are impossible owing to the low intensity of illumination which is necessary to reduce "flicker" to a convenient level. In such cases permanent records of individual

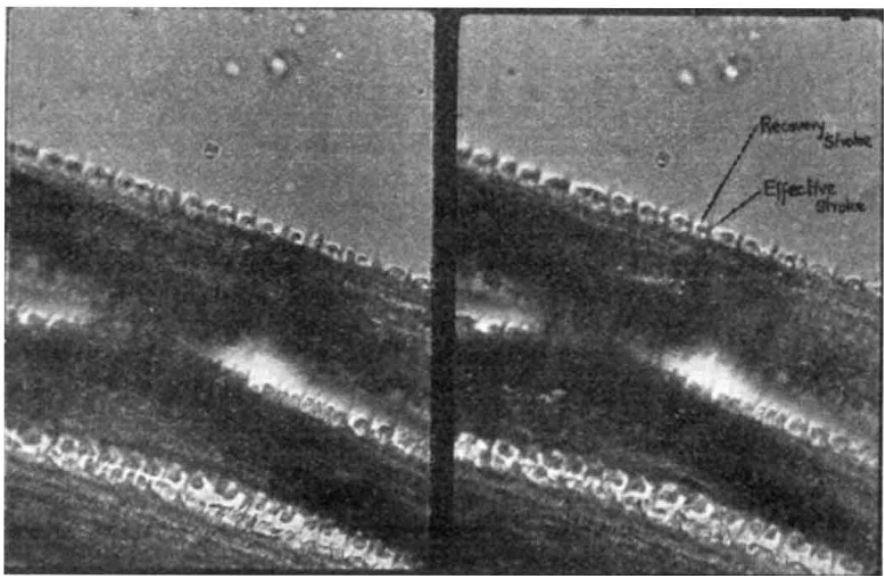

F1G. 1.-Two successive photographs of the metachronal waves passing over a ciliated epithelium. The cilia are seen in side view with their beat at right angles to the plane of the paper. Each wave has two components. (i) The dark finger-like processes representing cilia in the effective phase of their beat. (ii) Semicircular waves outlined by an illuminated edge, representing cilia in the recovery phase of their beat. The waves are travelling from right to left.

cilia or of the metachronal waves can be made by synchronising, with a variable speed stroboscope, the shutter of an ordinary cinematograph camera; in this way "slow motion' records of rapidly vibrating cilia can be obtained, and the frequency and velocity of beat can be determined with accuracy.

The lateral cilia on the gills of Mytilus edulis have been examined by these methods. The frequency of vibration of individual cilia varies, in different samples of tissue, from 5 to 16 vibrations per second at $22^{\circ} \mathrm{C}$., whilst the metachronal waves move over the epithelium with an average velocity of $100 \mu$ per second. The wave-length of the wave varies with the frequency of its constituent cilia, and the form of the wave may vary from time to time at any given point without interfering with the continuity of the whole wave system.

So far as is known, this constitutes the first successful attempt to estahlish a permanent record of ciliary activity. With the data thus available it is possible to analyse ciliary movement with accuracy, and we are no longer restricted to observations of the velocity at which particles move over the epithelium or to the behaviour of relatively inactive cilia.

It is interesting to note that the new methods illustrate very clearly the difference in the form of a cilium during the two phases of its beat, and that the nature and propagation of a metachronal wave is closely associated with the individual properties of the constituent cilia and do not appear to be the result of an extraneous timing mechanism. J. GRAY.

Zoological Dept., Columbia University, New York City.

\section{Horsetail Ghoking Field Drains.}

FIELD drains are commonly blocked by the roots of trees growing in their vicinity. Sycamore, ash elm, and naturally willow, are offenders in this respect; oak and beech rarely cause such trouble, at any rate in my experience. To find such mischief resulting from the rhizomes (underground stems) of the horsetail (Equisetum) was a revelation to me.

A wet patch developed recently in a pasture field here. The drains have just been examined and found to be stopped up in places by the matted rhizomes of Equisetum, presumably the common species, $E$. arvense. My man reported the matter to me, and said the stuff he had pulled out of the drain-pipes could not be tree roots, as there were no trees near, and besides the strands were soft and easily broken. $\mathrm{He}$ thought they might be the roots of 'sieves' - the local name for rushes (Juncus communis)--these weeds being now in evidence on the wet area. I greatly doubted this, and on investigation found the strands to be the underground stems of the horsetail. Hitherto I was un. aware that Equisetum grew in this field, but my man informs me that it was quite noticeable when the ground was last ploughed towards the end of the War; and evidently it still persists to some extent.

The rhizomes have great penetrating power, for they were found in the pipes at a depth of three and a half feet. In the cuttings made down to the drainage level, the rhizomes can be seen running here and there in the subsoil, but in no great abundance. In the pipes, however, they increase greatly, giving off at each node a number of roots which branch copiously, effectually blocking the drain. The rhizome is about the thickness of a straw and the root much finer. They are both almost black in colour.

Farmers in this district are well ac. quainted with the plant, knowing it by the name of 'paddock pipes.' It has an evil reputation of scouring cattle.

Blaithwaite,

JOHN PARKIN.

Wigton, Cumberland,

Dec. 11

Band Spectrum of Chlorine or Hydrogen Chloride.

IN the Zeitschrift für Physik for August, Kondratjew and Leipunsky describe the emission spectrum of chlorine heated in a silica tube to about $1000^{\circ} \mathrm{C}$. I compared their photograph with one taken by W. West and myself in 1924 of the flame of chlorine burning in hydrogen, which shows a continuous spectrum with a maximum at $480 \mu \mu$. I could find no record of the brand of plate used, so asked two honours students, Messrs. Reid and Soutar, to obtain a new photograph and compare it with the one obtained by simply heating chlorine. To my surprise a beautifully clear band spectrum was obtained.

The only difference in method I can recollect was that a silica jet was used for the chlorine instead of the platinum jet used in 1924. The continuous light is visible enough using a direct vision spectroscope, but is apparently of much less actinic intensity than the band spectrum in the apparatus now used. The flame is started by a spark from platinum wires connected to a small induction coil ; if the sparks are maintained while the photograph is being taken, the continuous emission spectrum at $260 \mu \mu$ is obtained as

No. 3090, VoL. 123] 